\title{
As exposições do IAC/MASP (1951-1953) e do IDI/MAM-RJ (1968-1978): institucionalização do design e industrialização
}

The exhibitions of IAC/MASP (1951-1953) and IDI/MAM-RJ (1969-1988): design

institutionalization and industrialization

\author{
Gustavo Cossio* \\ dsgcossio@gmail.com \\ Alexandre Schiavoni** \\ alexschi@yahoo.com.br
}

Resumo: Este estudo trata do papel relevante que determinadas exposições e instituições museológicas tiveram para a difusão do design moderno no Brasil. Os nomes aqui apresentados contribuíram com a organização e projetos de exposição de design que, hoje, acrescentamno estudo da história do design no Brasil. Assim, são analisadas as ações no nível institucional, com o foco em dois museus, o Museu de Arte de São Paulo - MASP e seu Instituto de Arte Contemporânea - IAC, e o Museu de Arte Moderna do Rio de Janeiro - MAM-RJ, que sediou o Instituto de Desenho Industrial - IDI. No primeiro, são importantes os nomes de Lina Bo e Pietro Maria Bardi e do designer Alexandre Wollner, para a exposição de Max Bill, no início dos anos 1950. Já a respeito do segundo, enfatizamos a atuação de Karl Heinz Bergmiller, a partir dos anos 1960, que desenvolveu sistemas expositivos para o MAM-RJ e, além disso, realizou as bienais de desenho industrial, nas dependências do museu. Importa ressaltar que uma das justificativas para a produção de exposições de design em instituições museológicas, a partir do período moderno, reside no fato de a inserção da atividadeemergir também em meio ao circuito artístico e cultural, no contexto de industrialização. Constata-se que a exposição museológica torna-se um dos meios para aproximar o público do design concebido em âmbito nacional, e também oportunizar o contato com projetos desenvolvidos em outros países. Por fim, é possível compreender que as exposições realizadas naqueles museus tiveram papel fundamental para a inserção de uma cultura de design no país.

Palavras-chave: história do design, exposição de design, design e educação

Abstract: This study is about the relevant role that certain exhibitions and museum institutions had for the dissemination of modern design in Brasil. The names presented here contributed to the organization and design exhibition projects which today add up to the study of design history in Brazil. Thus, the actions at the institutional level are analyzed, with the focus on two museums, the Museu de Arte de São Paulo - MASP and its Instituto de Arte Contemporânea - IAC, and the Museu de Arte Moderna do Rio de Janeiro - MAM-RJ, which hosted the Instituto de Desenho Industrial - IDI. In the first are important the names of Lina Bo and Pietro Maria Bardi, and designer AlexandreWollner, for Max Bill'sexhibition in the early 1950s. For the second, it is emphasized the role of Karl Heinz Bergmiller, which developed display systems for the MAM-RJ and, moreover, organized the industrial design biennials, in the museum's premises, from late 1960s. It is worth stressing that one of the justifications for the production of design exhibitions in museological institutions, from modern times onwards, is the fact that the inclusion of the activity also emerges amid the artistic and cultural circuit during the industrialization context. It appears that the museological exhibition becomes a way for the public to approach the design projects nationally developed, and also provide the opportunity for contact with projects developed in other countries. Lastly, it is possible to understand that the exhibitions held in those museums played a key role in the inclusion of a design culture in the country.

Keywords: design history, design exhibition, design and education

*Mestre em Design pela Universidade Federal do Rio Grande do Sul (UFRGS).

**Mestre em História pela Universidade Federal do Rio Grande do Sul (UFRGS). 


\section{Introdução}

O chamado processo de desenvolvimento de uma cultura não se mede somente pelo progresso e pelo enriquecimento economico, mas por um conjunto mais amplo e sutil de valores [...] Aos fatores economicos privilegiados até bem pouco foram acrescentados os fatores sociais e, já agora, a compreensão do todo cultural. $O$ Desenho Industrial surge naturalmente como uma disciplina capaz de se responsabilizar por uma parte significativa deste processo. (Aloisio Magalhães, 1973).

A formação e o portfolio da geração modernista de designers brasileiros são marcados por uma série de exposições. Nesse aspecto, torna-se válido retomar pontos importantes da história do design no país. Com o estudo da inserção no contexto nacional, é possível verificar o papel relevante que determinadas exposições e instituições museológicas tiveram para a difusão do design moderno. Do mesmo modo, as iniciativas teriam repercussão direta na formação dos profissionais da época.

De acordo com Niemeyer (2007), nas décadas de 1940 e 1950, se consolidou a ideia de que "as instituições culturais, além da conservação e exposição de obras de arte consagradas, deveriam se abrir para apresentar a arte livre e renovada de sua época" (NIEMEYER, 2007, p. 62). Os museus deveriam oferecer exposições temporárias e atividades didáticas, culturais e sociais - um conceito concretizado com a fundação do Museu de Arte Moderna de Nova York (MoMA), em 1929 ${ }^{1}$. Segue estes moldes o Museu de Arte de São Paulo (MASP), que inaugurou um ritmo intenso de ações pedagógicas a partir de outubro de 1947.Com efeito, vale mencionar o postulado de Lina Bo Bardi (1999) sobre a destinação social daquelas instituições: "os museus novos devem abrir suas portas, deixar entrar o ar puro, a luz nova. Entre passado e presente não há solução de continuidade. É necessário entrosar a vida moderna, infelizmente melancólica e distraída por toda espécie de pesadelos, na grande e nobre corrente da arte" (BARDI, 1999, p. 5).

Por sua vez, Schincariol (2009) ressalta o compromisso educacional daquelas instituições, pois eram constituídas, desde a origem, em sintonia com as discussões internacionais sobre a função social dos museus. Por isso, não estavam restritas à guarda e à preservação de patrimônio destinado a um público especializado, mas seriam lugares vivos e atuantes, que desejavam voltar-se para um público mais amplo. Em conformidade com a autora, os museus estabelecidos ao final da década de 1940 têm papel fundamental na consolidação do modernismo, com ações de formação, algumas marcantes para os direcionamentos do design e das vertentes abstratas das artes visuais, especialmente a construtiva.

Nesse sentido, destaca-se a contribuição de determinadas exposiçõesdurante a inserção do campo do design no país. Em uma perspectiva histórica, este artigo trata de uma análise sobre exposições que contribuíram para a difusão da atividade. O ponto de partida é o estágio inicial do ensino do design, no âmbito da sua relação com os museus, à época do cenário brasileiro de industrialização.Assim, são abordadas exposições de design com o foco no MASP e seu Instituto de Arte Contemporânea - IAC (1951-1953), e noMuseu de Arte Moderna do Rio de Janeiro - MAM-RJ, que sediou oInstituto de Desenho Industrial - IDI (1968-1978).

Esse estudo tem origem como parte da fundamentação teórica de uma dissertação de mestrado sobre o projeto de exposições de design ${ }^{2}$. A metodologia se

\footnotetext{
${ }^{1}$ A ideia concretizou-se também na Europa, onde a primeira instituição do gênero foi o Museu de Arte Moderna de Paris (NIEMEYER, 2007).

${ }^{2}$ Dissertação intitulada "Design de Exposição de Design - três estudos sobre critérios projetuais para comunicação com o público", de Gustavo Cossio, com orientação do prof. Dr. Airton Cattani, no Programa de Pós-graduação em Design da Universidade Federal do Rio Grande do Sul - PGDESIGN/ UFRGS, aprovada em novembro de 2011.
} 
baseia em uma revisão de literatura, que busca respaldo nos estudiosos da teoria e história do design, especialmente Bernard E. Bürdek (2010) e Tomás Maldonado (2009), bem como Ethel Leon $(2014 ; 2012 ; 2005)$, da Faculdade de Campinas - Facamp, Lucy Niemeyer (2007), Pedro Luiz Pereira de Souza (2008; 2004; 1996) e Rafael Cardoso (2008), docentes da Escola Superior de Desenho Industrial da Universidade Estadual do Rio de Janeiro - ESDI/UERJ. Os referenciais de Alexandre Wollner (2003) e André Stolarski (2005), e dos pesquisadores Maria Stella Tedesco Bertaso e Marcos da Costa Braga (2010) complementam o marco teórico.

\section{Desenvolvimento}

Nesta análise, tratamos de iniciativas em instituições relevantes para afirmação do design no país, com o enfoque nas exposições com fins educativos. Para isso, será traçado um breve panorama sobre a inserção do campo profissional do design em âmbito nacional, a partir de uma reflexão sobre as relações deste campo com o setor cultural e o desenvolvimento tecnológico. Os museus que apresentamos - MASP e MAM/ RJ - organizaram e projetaram exposições de desenho industrial que, hoje, são consideradas históricas para a atividade. No IAC/MASP, são importantes os nomes dos diretores Lina Bo e Pietro Maria Bardi e do designer Alexandre Wollner, para a exposição de Max Bill, no início dos anos 1950. Já a respeito do IDI/MAM-RJ, enfatizamos a atuação de Karl Heinz Bergmiller, a partir do final dos anos 1960, que desenvolveu dois sistemas expositivos para o museu. Além disso, juntamente com Goebel Weyne e os seus colegas, realizou as bienais de desenho industrial, nas dependências do MAMRJ.

\section{O design na periferia: industrialização e institucionalização do design no Brasil}

A institucionalização do design no país se dá no contexto de industrialização das décadas de 1950-6033. A partir do governo de Juscelino Kubistchek (1956-61) ocorre o crescimento acelerado da nossa economia, denominado de desenvolvimentismo. É promovida a internacionalização da nossa economia com a vultosa entrada de multinacionais e de enormes volumes de capital estrangeiro tomados como empréstimo pelo governo federal. Soma-se a isto a realização de investimentos diretos que eram seguidos por intensa emissão de moeda. $\mathrm{Na}$ indústria se desenvolveram os bens de consumo duráveis incluindo automóveis e eletrodomésticos. A construção de Brasília, o surgimento do Cinema Novo, da Bossa Nova e do Concretismo reforçava o clima de otimismo e deixava claro que o Brasil caminhava a largos passos em direção ao desenvolvimento (DEL PRIORE; VENÂNCIO, 2010; VERSIANI; SUZIGAN, 1990). Havia, contudo, um setor a ser trabalhado: o da indústria. Os países desenvolvidos, neste quesito ainda nos superavam e, há pelo menos cem anos, investiam no que denominavam de design.

A definição precisa do que venha a ser o design foi tema polêmicodesde seu nascimento. Ao conceituar o termo, Bürdek (2010, p. 13) remonta à primeira definição, pelo Oxford Dictionary, em 1588: “um plano desenvolvido pelo homem ou um esquema que possa ser realizado". Contudo, o sentido atual daquilo que denominamos design surge no contexto da Revolução Industrial, em meados do século XIX, quando a divisão do trabalho separou - o que até então era feito pela mesma pessoa - o projeto do objeto da sua manufatura, da sua produção. Já no século XX, conforme a defini-

\footnotetext{
${ }^{3}$ Embora haja iniciativas anteriores, especialmente no âmbito das artes gráficas com a produção de periódicos, é a partir dos anos 1950 e 1960 que o design se afirma no Brasil, com o surgimento dos primeiros cursos de formação e a incipiência da indústria. Sobre os primórdios da atividade no período anterior, ver CARDOSO, Rafael. O design brasileiro antes do design: aspectos da história gráfica, 1870-1960. São Paulo: Cosac Naify, 2007.
} 
ção estabelecida pelo International Council of Societies of Industrial Design - ICSID, de 1959, prevalece a ideia de que o design

é uma atividade criativa que consiste em determinar as propriedades formais dos objetos produzidos industrialmente. Por propriedades formais não se entende somente as caracteristicas exteriores, mas, sobretudo, as relações funcionais e estruturais que fazem com que o objeto tenha uma unidade coerente tanto do ponto de vista do produtor quanto do usuário. Ao design industrial estende-se a adoção de todos os aspectos do ambiente humano condicionados pela produção industrial (CARA, 2010, p. 22).

Sobre essa definição, Tomás Maldonado (2009) destaca sua limitação, informando que ali o design é concebido apenas como realização de uma especialidade técnica. O autor cita que, além do valor estético (ou estético-funcional), o design considera "os fatores relativos ao uso, fruição e consumo individual ou social do produto (fatores funcionais, simbólicos ou culturais), como aos que se referem a sua produção (fatores técnico-econômicos, técnico-construtivos, técnicosistemáticos, técnicos produtivos e técnicodistributivos)" (MALDONADO, 2009, p. 14).

No que se refere as suas vertentes, segundo Bürdek (2010), a divisão entre trabalho técnico e de configuração do produto fez com que a atividade apresentasse, nos inícios do século $\mathrm{XX}$, duas variantes projetuais: uma norte-americana e outra europeia. Nos Estados Unidos se desenvolveu o Styling, enquanto na Europa, particularmente na Alemanha de Weimar, no pósPrimeira Guerra Mundial, é criada a Bauhaus, considerada um dos maiores paradigmas do ensino do design. No desenvolvimento do projeto, o Styling privilegia a forma: o modo como o objeto vai ser visto, percebido e recebido pelo público, é o fundamental nesta vertente. O contexto em que o Styling está emergindo, o Entreguerras, caracteriza-se pela produção acelerada nos EUA e pela retomada do crescimento na Europa. Nesta perspectiva, havia a tendência dos europeus diminuírem suas importações de produtos norteamericanos, redundando em sérios problemas para a economia dos EUA. Neste quadro é que emerge o Styling, acenando com a possibilidade de se manter as vendas em alta, bastando para isso oferecer ao consumidor novos produtos com regularidade e rapidez. Para isso, seria necessário intervir sobre, fundamentalmente, a forma dos objetos, alterando-lhes a carcaça, mantendo igualmente a estrutura interna, o funcionamento, os componentes. É nesse momento que objetos - inicialmente os eletrodomésticos sofrem pequenas alterações visuais - formato, cor, textura - sendo apresentados de tempos em tempos como a última novidade, como o que o mercado oferece de mais moderno. Em realidade, a estrutura e a função de todos os modelos apresentados como novos, era a mesma. Porém, foi isso que garantiu as linhas ascendentes das vendas das empresas. ${ }^{4}$

Quando se examina a corrente projetual europeia, percebe-se que a abordagem era bem distinta da norte-americana, particularmente aquela inaugurada pela Bauhaus. Enquanto o Styling não constituiu escola ou movimento organizado de design, sendo marcado pela produção original de indivíduos que se dedicavam à projetação, a Bauhaus, ainda que não possa ser considerada um movimento, originou uma escola que se dedicou ao ensino do design. A produção originária da escola caracterizou-se pela configuração práticofuncional, cuja aparência visual fundamentou-se em uma teoria estética elementar ${ }^{5}$. Fundada em 1919, a

\footnotetext{
${ }^{4}$ Para uma abordagem alternativa sobre o Styling, consulte-se CARDOSO, Rafael. Uma introdução à história do design. São Paulo: Edgard Blücher, 2008, pp. 136-150. Na visão de Cardoso (2008) o Styling, tem sido demonizadoa partir de uma leitura modernista, obscurecendo para o campo a contribuição dos seus designers.

${ }^{5}$ Atenta às manifestações culturais, a Bauhaus empregou elementos do desenho provenientes de movimentos artísticos modernistas como o Cubismo, o Construtivismo russo e o De Stjil, os quais abstraíram os elementos visuais à figuras geométricas como o quadrado, o círculo e o triângulo equilátero, e às cores primárias, amarelo, azul e vermelho (LUPTON; MILLER, 2009; SOUZA, 2008).
} 
Bauhaus, buscando atingir uma nova síntese, articulou as condições sociais, políticas e tecnológicas apontando para os elementos basilares no design: a simplificação e a padronização. Através da exploração de dois fatores inerentes à cultura industrial, a produção de menor custo econômico e uma estética própria, foi possível obter o design de configuração formal simples, isento de ornamentos, típico da produção serial do século XX. A escola foi fechada em 1933 com a ascensão do nazismo.

No pós-Segunda Guerra Mundial, um projeto similar, a Hochschule für Gestaltung, HfGou Escola Superior da Forma (1953-1968) surge em Ulm, Alemanha. Compartilhando o mesmo ideário bauhausiano, a Escola de Ulm (HfG) concebe o design como uma influência reformadora da sociedade. Porém, o modelo ulminiano incorpora o avanço científico e tecnológico, em novas disciplinas com ênfase em ergonomia, métodos qualitativos e quantitativos, além do rigor metodológico. No ensino da comunicação visual, as formas eram acreditadas como puras, claras e despojadas (BÜRDEK, 2010; CARDOSO, 2008; CURTIS, 2010; LUPTON; MILLER, 2009; SOUZA, 2008).

No Brasil, a necessidade de se estabelecer o estudo e a aplicação sistemática do design se dá, de fato, com a instalação da Escola Superior de Desenho Industrial - ESDI, no ano de 1962, cuja concepção pedagógica incorpora o modelo da Escola de Ulm. Ressalta-se o vínculo daquela geração de designers - composta em boa parte por imigrantes e nomes de ascendência estrangeira - com o modernismo europeu e a ordem soci- al, política e econômica, vigente no cenário nacional. O país, durante o período inicial de industrialização, passava por uma transição, na qual havia a necessidade da afirmação de uma 'unidade nacional' através da valorização de nossas fontes históricas, étnicas e culturais. Isso significava que a configuração de nossa cultura material deveria ser elaborada segundo os cânones do modernismo ${ }^{6}$, atendendo as exigências da reprodução das condições sociais. Portanto, o designer deveria atuar ao lado e a favor dos processos produtivos e seus meios, dentro da lógica capitalista requisitada pela modernização do Estado nacional (NIEMEYER, 2007).

No compasso das políticas nacionalistas e desenvolvimentistas de governos embalados por slogans como cinquenta anos em cinco $^{7}$, Cardoso (2008, p. 178) sublinha que "o design brasileiro se viu levado a gerar soluções à altura dos grandes desafios sociais e culturais da época”. Conforme o autor, os profissionais buscavam por formas gerais e supostamente universais, de preferência redutíveis a módulos simples e abstratos que pudessem ser eternamente recompostos de acordo com necessidades funcionais. Os designers da segunda fase modernista se viram divididos entre nacionalismo e internacionalismo, entre tradição artesanal e progresso industrial. A partir de então, o design tem lidado com a contradição entre a posição do Brasil como país periférico e o perfil cultural do design como uma atividade 'de ponta' em termos tecnológicos ou 'de vanguarda' em termos estilísticos. A origem do ensino do design no país ocorreu nas regiões em que o processo de industrialização mais avançava, o centro-sul. Em São Paulo, o curso do IAC-MASP representa o embrião

\footnotetext{
${ }^{6} \mathrm{~A}$ influência da doutrina estetica raconalista no design pode ser compreendida como uma utopia social e um vocabulário plástico cujas sintaxes buscavam sua lógica naquele princípio de harmonia universal, em uma unidade por trás da diversidade das coisas e uma semelhança entre tudo que existe apesar de suas formas, na analogia entre o micro e o macro. A ideologia do Estilo Internacional se baseava na ideia de que a criação de formas universais reduziria as desigualdades e promoveria uma sociedade mais justa. No entanto, a ironia histórica em relação ao Estilo Internacional reside no fato de ter sido utilizado como padrão de comunicação das corporações multinacionais (NIEMEYER, 2007).

${ }^{7}$ Lema do Plano de Metas do presidente Juscelino Kubitschek. A construção da nova capital, Brasília, foi a imagem mais eloquente de seu governo. O projeto de Oscar Niemeyer era a expressão em concreto de uma ideologia e concepção de poder: impactante, forte, audaz e inovadora. A fala de JK expressava o tipo de ação do governo e a sua visão de futuro: "industrializar aceleradamente o país; transferir para o nosso território as bases do desenvolvimento autônomo; fazer da indústria manufatureira o centro dinâmico das atividades econômicas nacionais - isto resumia o meu propósito, a minha opção" (NIEMEYER, 2007).
} 
da institucionalização da atividade. A proximidade dos acontecimentos aponta a urgência do problema: o MASP foi fundado em 1947 e em 1951 foi criado o IAC (CARDOSO, 2008; LEON, 2014).

Já início da década de 1960, quando da criação da ESDI, no Rio de Janeiro, o panorama político e econômico havia sofrido algumas alterações. O Plano de Metas de JK e os resultados do desenvolvimentismo trouxeram uma série de problemas que deveriam ser equacionados: crescente endividamento externo, inflação disparando, Produto Interno Bruto - PIB decrescendo, multinacionais enviando altos percentuais de lucros para o exterior. Tudo isso estruturava um modelo de desenvolvimento muito dependente do capital externo. Os prejuízos sociais eram imensos e tendiam se expandir (VERSIANI; SUZIGAN, 1990).

Particularmente no governo de João Goulart (1961-64) a tentativa de correção dos rumos abertos pelo Plano de Metas desaguou no enfrentamento entre duas forças antagônicas. Por um lado, havia grupos que defendiam a retomada de outro modelo de crescimento, já iniciado por Getúlio Vargas nas décadas de 1930 e 1940, investindo cada vez mais numa solução nacionalista, e por outro, os chamados liberais que insistiam afirmar que o crescimento acelerado só seria possível pagando um determinado preço que pressupunha a associação mais íntima com o capital externo (SCHWARCZ; STARLING, 2015). Pois é neste quadro polarizado que se institucionaliza o design no Brasil. A atividade emerge como resultado de uma necessidade identificada já na década de 1950 e surge caminhando lado a lado com os museus de arte do centro industrial do país.

\section{As exposições do Instituto de Arte Contemporânea - IAC/MASP}

Eu só tive a certeza de que queria mesmo fazer design quando o Max Bill veio fazer sua exposição no IAC. Fiquei atônito com a exposição [...] quando vi a exposição do Max Bill, minha intuição bateu e vi que era isso, meu caminho é esse. E, quando explode em você algo que estava adormecido, você acorda e vai procurar estudar. (Alexandre Wollner, 2003).

Em seu estudo sobre a inserção do design no contexto nacional, Niemeyer (2007) localiza o MASP como o lugar em que "o design passou a ser sistematicamente tratado, seja em suas atividades didáticas e exposições, seja nos seus equipamentos"(NIEMEYER, 2007, p. 63). Foi estabelecido no museu, em 1951, sob a direção de Pietro M. Bardi, o Instituto de Arte Contemporânea - IAC, que ofereceu o primeiro curso de desenho industrial da América Latina e originou o ensino do design no Brasil, com influências da Bauhaus e da Escola de Chicago (BARDI, 1993; LEON, 2014; NIEMEYER, 2007; WOLLNER, 2003).

Nesse âmbito, Anelli (2009) refere-se ao historiador da arte Giulio Carlo Argan para caracterizar a ligação do IAC com o MASP: “uma escola de indústria ou design que assumisse o museu como um fundamento da própria atividade didática atingiria, seguramente, a resultados de uma novidade surpreendente" (ARGAN apud ANELLI, 2009, p. 12). O autor afirma que o instituto não tinha por objetivo unicamente a formação de especialistas e a visitação ocasional de um público curioso: exposição de arte antiga e contemporânea em um espaço moderno também destinado ao design moderno acentua um vínculo que ficaria explícito com a criação do IAC junto ao MASP. Assim, o instituto seria a base da construção de uma nova cultura contemporânea, disseminada na produção industrial, sendo que a expografia constituía apenas um importante instrumento dessa ação (ANELLI, 2009).

Coordenados por Lina Bo Bardi, os professores Carlos Bratke, Flávio Motta, Gregori Warchavichik, Jacob Ruchti, Lasar Segall, Roberto Sambonet, Roger Bastide e Salvador Candia, atenderam uma turma de trinta jovens (a maioria bolsistas entre paulistas, gaú- 
chos e argentinos), ao proporcionar acesso às informações, à metodologia e ao treinamento do processo criativo no desenho industrial. O IAC formou os primeiros designers brasileiros ativos: Alexandre Wollner, Antô-

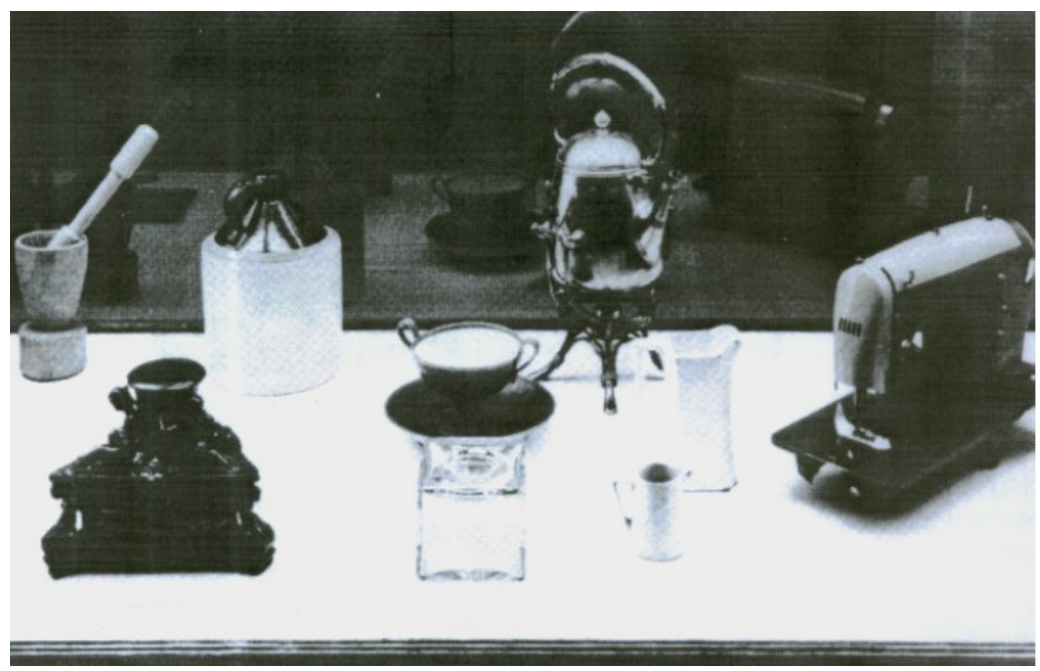

mesma coisa que o pote na época do pote: um objeto útil, que fazia parte da cultura de um grupo primitivo, assim como hoje a máquina de escrever faz parte do nosso grupo. Foi então que comecei a perceber essas coisas (STOLARSKI, 2005, p. 37).

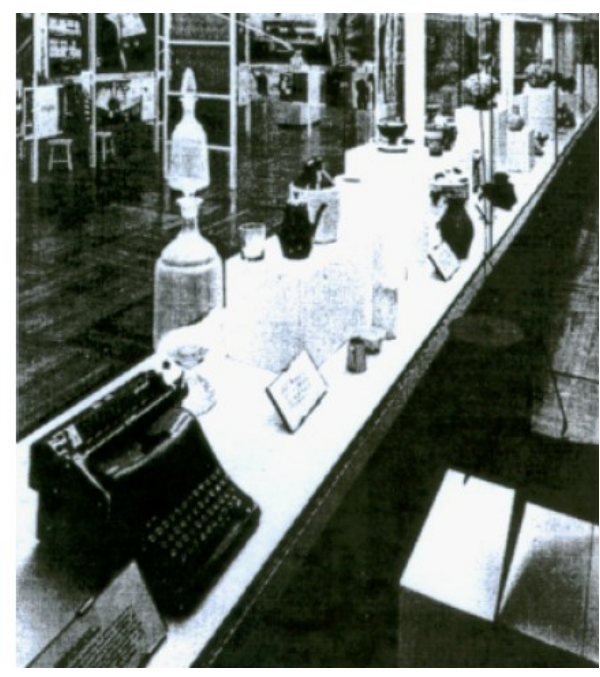

Figura 1-Vitrine das Formas no IAC/MASP. Fonte: Leon (2014).

Figure 1-Vitrine das Formas at IAC/MASP. Source: Leon (2014).

nio Maluf, Aparício Basílio da Silva, Carlos Galvão Krebs, Emilie Chamie, Estella T. Aronis, Irene Ivanovsky Rucchi, Isolde Brams, Lauro Pressa Hardt, Lígia Fleck, Ludovico Martino, Luiz Hossaka Marion Koch, Maurício Nogueira Lima, Vírginia Bergamasco e Yone Maria de Oliveira (BARDI, 1993; LEON, 2014; NIEMEYER, 2007; STOLARSKI, 2005; WOLLNER, 2003).

Para a surpresa do então estudante Alexandre Wollner (2003) e seus colegas do IAC, o professor Bardi expôs a máquina de escrever da Olivetti junto ao acervo clássico do museu, conforme a figura 1. Wollner recorda:

Um dia vi uma vitrine cheia de potes egípcios, astecas, e, ao lado de diversas outras antiguidades, uma máquina Olivetti. Fui falar com o Flávio Motta que era assistente do Bardi: 'Acho que esqueceram uma máquina de escrever na vitrine...' O Bardi se interessou pelo sujeito que havia dito aquilo e veio me explicar que a máquina de escrever era a
Além de uma exposição sobre a Olivetti e outra sobre cartaz suíço, Pietro Maria Bardi promoveu também a primeira exposição retrospectiva, por ocasião da inauguração do IAC. Tratava-se dos trabalhos do pintor, designer, publicista e arquiteto suíço Max Bill ${ }^{8}$, idealizador, coordenador e reitor, na época, da Escola de Ulm. Bill era então um dos maiores nomes da arte concreta e não fazia distinção entre a sua atividade como artista, designer ou arquiteto e, analogamente, a sua exposição incluía obras de arte, produtos gráficos e objetos industriais (LEON, 2014; STOLARSKI, 2005).

Naquela ocasião, o professor Bardi convidou Alexandre Wollner para a montagem de uma exposição de um designer suiço famoso, expressa na figura 2. Ao relembrar a ocasião, seu primeiro trabalho profissional, Wollner afirma que aquela vivência oportunizou-lhe uma percepção de que "o desenho [...] podia adaptar-se para criar produtos, formas novas. Fiquei paralisado.

\footnotetext{
${ }^{8}$ Max Bill foi aluno da Bauhaus, mas ficou impossibilitado de concluir o curso devido a um acidente que acarretou em problemas de saúde. Foi referência para o ensino no IAC/MASP.
} 
Foi um choque. Nesse momento, saí da idade das trevas" (STOLARSKI, 2005, p. 37).

A exposição no MASP divulgava os trabalhos de Max Bill, sendo que a Escola de Ulm era mencionada no texto de abertura, assinado por Pietro Maria Bardi. Apesar da relevância daquela exposição, conforme Wollner, nenhum crítico de arte, à época, falou ou escreveu a seu respeito - mas houve comentários a respeito da palestra em que Bill fez críticas à arquitetura de Oscar Niemeyer (STOLARSKI, 2005).

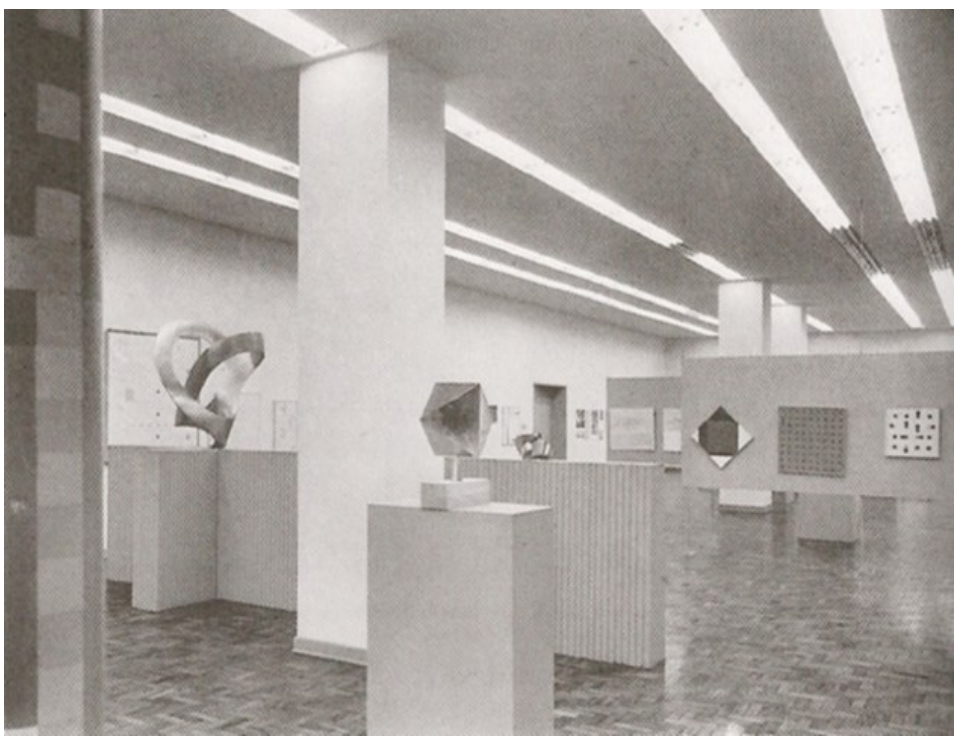

Figura 2-Vista da exposição de Max Bill, no MASP, no início dos anos 1950. Fonte: Bardi (1993).

Figure 2-View of Max Bill exhibition at MASP, in early 1950s. Source: Bardi (1993).

Para Wollner (2003), “a exposição de Max Bill foi o ponto esclarecedor da importância do design no processo cultural e industrial e influenciou a todos os estudantes do IAC" (WOLLNER, 2003, p. 70). Ao relembrar a sua formação e a mostra, o designer descreve:

O IAC, e principalmente a vivência e a convivência no ambiente do MASP daqueles anos (1951-53), aprimoraram minha capacidade intuitiva e permitiramme perceber a possibilidade de participação social do artista através do design. Esta percepção confirmou-se por volta de 1953, quando da exposição do pintor, escultor e designer suiço, Max Bill, no próprio MASP. Tal exposição veio de encontro às minhas tendências, ainda potenciais, no sentido de fundamentar minhas criações em raciocínio lógico e de participar de realizações objetivas e eficientes no âmbito social. Informou-me ainda sobre o projeto de Max Bill relativo à organização de uma escola de design, de nivel equivalente ao da Bauhaus, em Ulm, na Alemanha Ocidental (WOLLNER, 2003, p. 44).

A respeito da importância que o IAC representa para a história do design no Brasil, Niemeyer (2007) acrescenta que o instituto e as suas exposições estimularam a discussão sobre a relação entre design, arte, artesanato e indústria. A autora explica que a instituição buscou uma aproximação com o setor produtivo, de tal modo que Bardi conseguiu que algumas fábricas, como a Cristais Prado e o Lanifício Fileppo, abrissem suas portas aos alunos do curso.

Ainda conforme Niemeyer (2007), a breve existência do IAC - apenas três anos por insuficiência de recursos, após convênio com a prefeitura - ensejou o contato com correntes de pensamento que prevaleceriam no ensino formal de design no Brasil, do qual foi pioneiro. Nesse sentido, Leon (2014) explica que a relevância do IAC/MASP transcende o fato de ter sido 'a primeira escola de design do Brasil', pois reside na reunião de um corpo docente e discente capaz de conformar um campo de trabalho que se tornaria importante para a sociedade brasileira nas décadas vindouras.

\section{As exposições do Instituto de Desenho Industrial - IDI/MAM-RJ}

Além dos novos museus da capital paulista, a abertura do Museu de Arte Moderna do Rio de Janeiro - MAM-RJ, também se faz importante para a história do design no Brasil. O curso de design dessa instituição foi acolhido pela UNESCO, quando seu representante, Georges-Henri Rivière, clamou em evento sobre a Finalidade Educativa dos Museus que "se acentue o tema 'educação' e que se trate das atividades educativas do Museu" (NIEMEYER, 2007, p. 73). O curso da Escola Técnica de Criação do Instituto de Belas Artes do 
MAM-RJ não saiu do papel, mas a sua proposta foi absorvida pela Escola Superior de Desenho Industrial ESDI, a primeira graduação em design do país, fundada em 1962, com o início de suas atividades em 1963, no governo de Carlos Lacerda (CARDOSO, 2008; NIEMEYER, 2007; STOLARSKI, 2005).

Cumpre citar também a experiência do Instituto de Desenho Industrial - IDI (1968-1989), um organismo de pesquisa, divulgação e consultoria em design, instalado no MAM-RJ. Leon (2005, p. 100) assevera que"o IDI, como instituto de pesquisa, não sofria pressões de mercado e nunca competiu com escritórios privados. Pôde empreender projetos de fôlego, definidos a partir de prioridades sociais e econômicas". Nesse sentido, Wollner (2003) acrescenta que o instituto desempenhou um importante papel na formulação dos primeiros programas oficiais, vinculado a instituições, principalmente governamentais, no desenvolvimento de projetos, pesquisas e normas em desenho industrial. $\mathrm{O}$ autor explica ainda que o IDI assimilou, em seu corpo funcional, vários ex-alunos da ESDI.

O IDI marcou a trajetória dos profissionais e estudantes que participaram dele. Entre os designers que trabalharam no IDI estão Freddy van Camp, Gláucio Campelo, João Luiz Conde, Klaus Dieter Nagel, Lincoln Nogueira, Luiz Alberto Zuniga, Maria Beatriz Afflalo Brandão, Mario Ewerton Fernandez, Roberto Lanari, Sonia Ramalhete de Aguiar e Washington Lessa. Entre os redatores do Instituto figuraram Décio Pignatari, Luis Sérgio Ventura e Zuenir Ventura (LEON, 2012; 2005).
O convite para a estruturação do IDI foi feito a Karl Heinz Bergmiller ${ }^{9}$ pelo arquiteto Maurício Roberto, primeiro diretor da ESDI e então diretor do museu (WOLLNER, 2003; LEON, 2005). Bergmiller formouse na Hochschule für Gestaltung Ulm, na Alemanha, em 1958, e trabalhou no estúdio de Max Bill. Veio para o Brasil com bolsa do governo brasileiro no fim daquele ano, fixando-se em São Pauloe criou um sistema próprio de montagem para o MAM-RJ, sendo o coordenador de exposições no período entre 1968 e $1977 .{ }^{10}$

O primeiro sistema expositivo foi desenvolvido em 1967, projetado a partir de painéis removíveis, tanto em relação à obra-ambiente-visitante, como à técnica de organização e montagem. Ao pontuar que se tratava mais do que um sistema expositivo, Souza (2004, p. 17) explica que o projeto de Bergmiller "indicava uma forma de ordenação sistemática das atividades do museu". Bertaso e Braga (2010) acrescentam que o sistema modular (figura 3) constituía a identidade do projeto:

as relações sistêmicas permitiam a montagem de uma ou mais exposições, concomitantes ou não. [...] O problema colocado era primeiramente resolver as relações de tempo-espaço implicadas em montagem de exposições, ou seja, como erigir uma estrutura expositiva, dentro de uma programação museográfica, em um determinado periodo de tempo. A partir de um gráfico tempo-espaço determinou-se a real necessidade para o local. Adotou-se assim o projeto de um sistema estrutural de meios painéis e painéis em forma de $L, U$ ou $Z$. A partir de peças planas únicas e suportes respectivos, configurava-se um grande jogo de montar. Possibilitava-se a formação de ambientes que possuiam como característica o movimento, ou a limpeza visual (BERTASO; BRAGA, 2010, p. 7-8).

\footnotetext{
${ }^{9}$ Pedro Luiz Pereira de Souza e Silvia Steinberg, ex-alunos de Bergmiller na ESDI, passaram a fazer parte da coordenação do IDI, juntamente com Bergmiller e Goebel Weyne, a partir de 1972 (LEON, 2005; SOUZA, 2004).

${ }^{10}$ Bergmiller trabalhou no primeiro escritório de design do Brasil, o forminform, sociedade de Geraldo de Barros, Alexandre Wollner, Ruben Martins e Walter Macedo. Além disso, participou da fundação da ESDI, onde lecionou até 1998. Recorreu aos conhecimentos de médicos para iniciar os ensinamentos de ergonomia, que começaram a ser aplicados na escola, em 1966, seguindo o modelo de Tomás Maldonado da Escola de Ulm (LEON, 2005).
} 

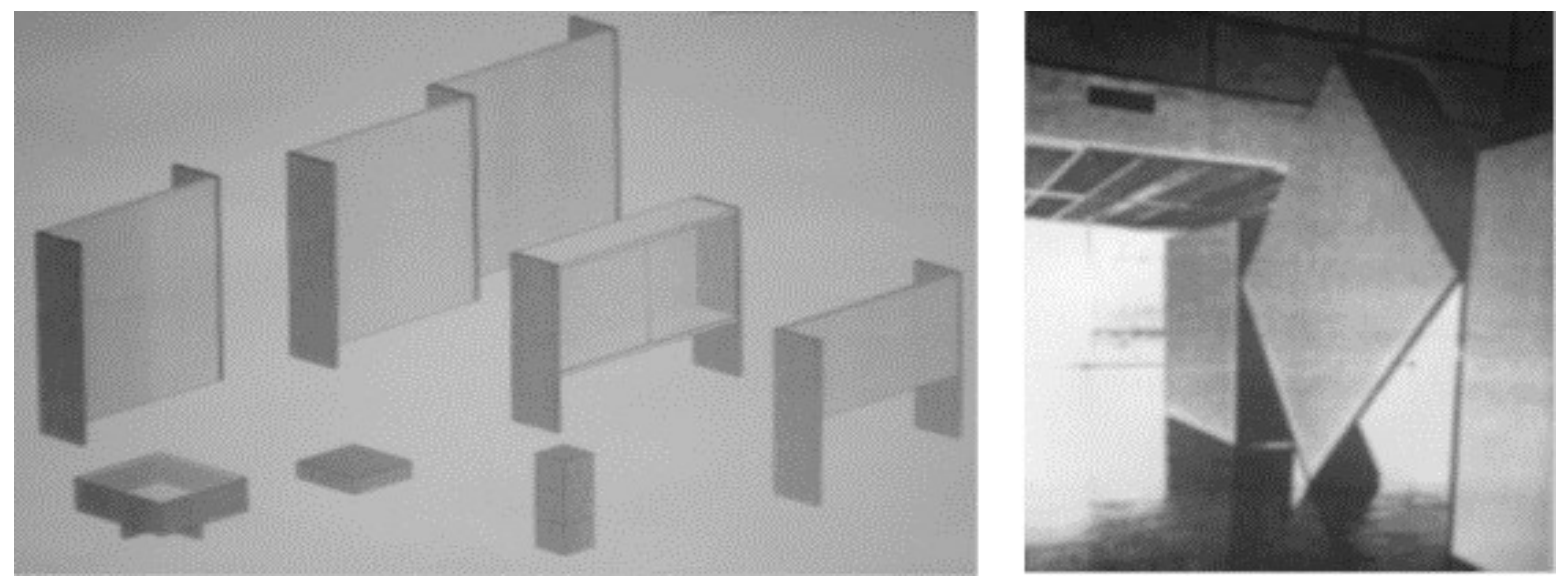

Figura 3-Primeiro sistema expositivo de Bergmiller e organização do espaço.Fonte: Bertaso e Braga (2010). Figure 3-First exhibition system by Bergmiller and organization of space. Source: Bertaso and Braga (2010).

Os autores enfatizam o caráter inovador daquela solução expográfica ao analisar o método sofisticado empregado pelo designer:

os montadores recebiam esquemas da disposição de cada obra, com o gabarito de alturas e alinhamentos. Bergmiller pontuava que o esquema de uma montagem precisava funcionar como uma indústria: em quatro turmas, a primeira fixava os painéis, a segunda trabalhava com as ferragens, a terceira fazia a colocação dos quadros e a última identificava as obras. As gravuras eram fixadas sobre os painéis, cobertas com um vidro do mesmo tamanho do painel. As esculturas ou volumes eram posicionados sobre cubos pretos, estes sobrepostos, justapostos, ou de acordo com a necessidade (BERTASO; BRAGA, 2010, p. 8).

Assim, identificamos o rigor com que o designer projetou aquele primeiro sistema expositivo. A proposta de Bergmiller resultou em flexibilidade ao sistema. Além disso, denotava a preocupação da exposição como meio de comunicação, uma vez que previa uma ordem para a informação em relação ao conteúdo. Portanto, a literatura ressalta a adequação do projeto às necessidades do museu.

No contexto da inserção do desenho industrial entre exposições e instituições museológicas brasileiras nos anos 1950 e 1960, outro nome importante é o do cearense Gustavo Goebel Weyne Rodrigues (1933-
2014). Goebel Weyne foi artista autodidata, que desenvolveu interesse pelo design. Além de participar da montagem das Bienais Internacionais de Arte, enquanto bolsista do MAM-SP, foi premiado pelo cartaz da nona edição, em 1967. No Rio de Janeiro, participou como professor da ESDI, a partir de sua fundação. Wollner (2003) registra que Goebel, por influência do seu conterrâneo Aldemir Martins, ligou-se ao desenvolvimento do design americano. ${ }^{11}$

O IDI foi encarregado pela montagem das bienais internacionais de desenho industrial, ocorridas em 1968, 1970 e 1972, e a atuação de Goebel Weyne foi determinante para a realização daquelas exposições no MAM-RJ. Um destaque de seu portfolio é o cartaz para a primeira edição, em 1968. De acordo com a análise de Melo (2008),

nos mostra um mestre em pleno domínio de seu léxico [...] toda a requintada construção visual se resume à maneira como o texto e os vazios são ordenados. $O$ ano grafado em vermelho cria na peça um ponto focal, além de dar o necessário apoio à suave dança das linhas de texto. $O$ bloco tipográfico está localizado abaixo do eixo horizontal do cartaz, ampliando e transformando em desenho o vazio da metade superior. Definitivamente, este é um exemplo maior da máxima modernista 'menos é mais' (MELO, 2008, p. 50).

\footnotetext{
${ }^{11}$ Wollner (2003) cita a influência de M. F. Agha, Alexey Brodovitch, Paul Rand, William Golden, Lester Beal, Will Burtin, AlvingLustig, LadislavStunar, Bradbury Thompson, Saul Bass e Leo Lionni.
} 


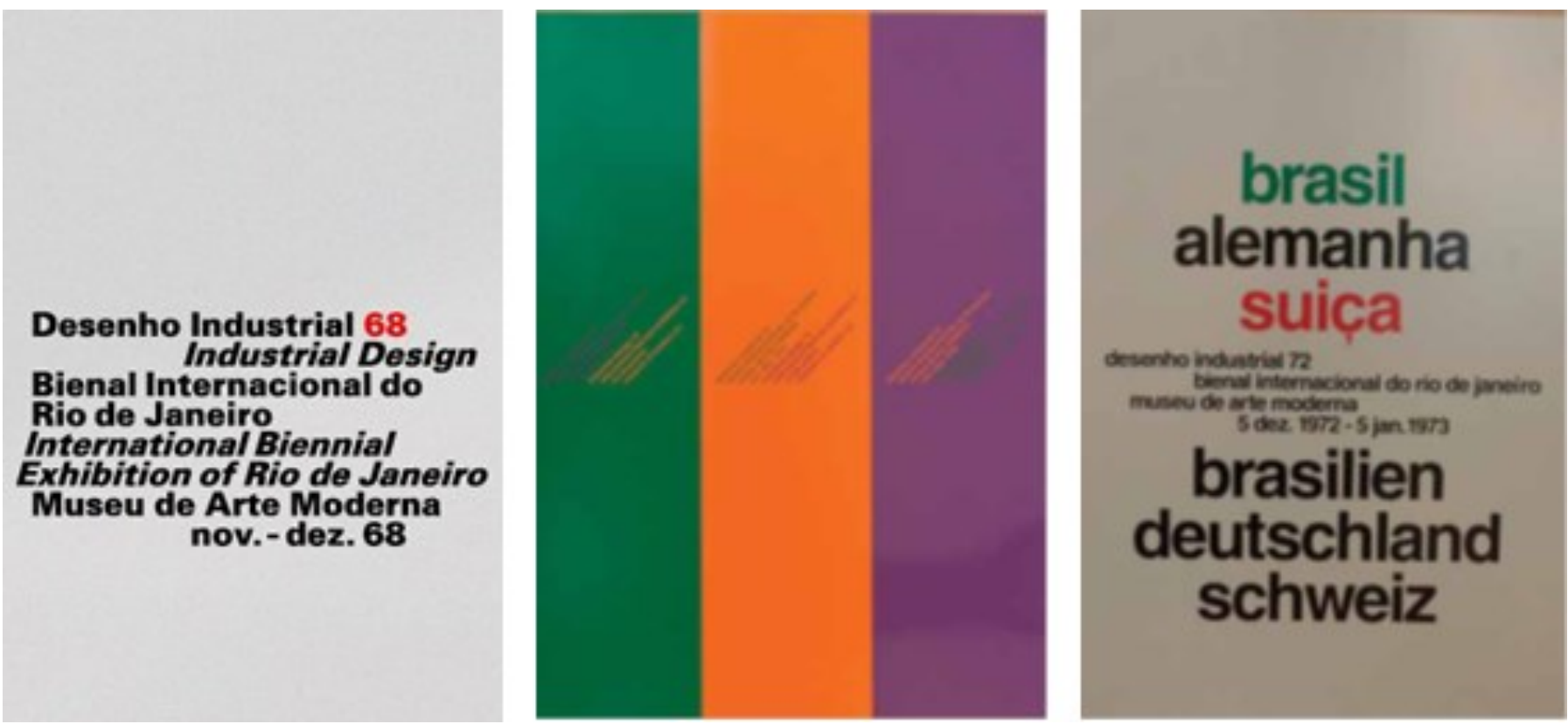

Figura 4-Cartaz da primeira bienal de desenho industrial, em 1968, da segunda edição, em 1970 e da terceira, em 1972. Fonte: Melo (2008); Van Camp e Fontoura(2010).

Figure 4-Poster of the first biennial of industrial design in 1968, the second edition in 1970 and third in 1972. Source: Melo (2008); Van Camp and Fontoura (2010).

Sobre os objetivos das bienais de desenho industrial, Van Camp e Fontoura (2010) explicam que já havia a certeza de que deveria ser feito um esforço promocional do design, não só para esclarecimento da sociedade e do grande público de que dominávamos o tema, mas especificamente para a criação de um mercado de trabalho para os egressos das instituições de ensino. A respeito da primeira edição da bienal, Leon (2012; 2005) aponta que a Desenho Industrial 68 Bienal Internacional do Rio de Janeiro, foi organizada pelo Ministério das Relações Exteriores, pelo Museu de Arte Moderna, pela ESDI, pela Associação Brasileira de Desenho Industrial - ABDI, pela Fundação Bienal de São Paulo e pela Confederação Nacional da Indústria.

Além da apresentação de dez trabalhos de designers brasileiros, a bienal trouxe uma seleção de três países - Estados Unidos, Canadá e Grã-Bretanha - e também os projetos da ESDI. Destaca-se a mostra da escola, O Banquete do Consumo(figura 5), que criticava o design orientado para o acúmulo de gadgets e a reprodução de um pensamento projetual importado, em uma desvinculação às condições sociais do Brasil na época.
Como exemplo, pode-se citar o aspirador de pó acompanhado de uma vassoura: do que adiantava uma obsessão pelos novos eletrodomésticos, em um país com mão de obra barata adaptada ao uso de vassouras? (SOUZA, 1996; LEON, 2012).

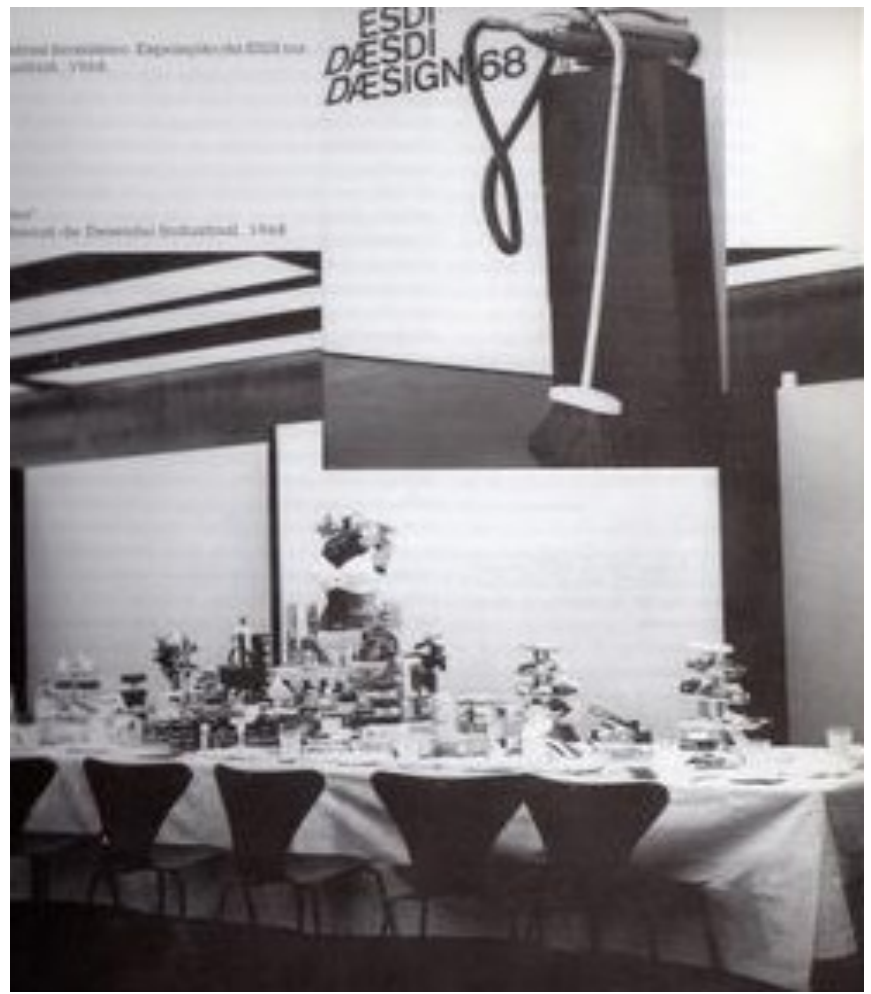

Figura 5-Exposição $O$ Banquete de Consumo, da ESDI, na Desenho Industrial 68 Bienal Internacional do Rio de Janeiro. Fonte: Souza (1996).

Figure 5-O Banquete de Consumo, an ESDI exhibition at the International Biennial of Rio de Janeiro. Source: Souza (1996). 
$\mathrm{Na}$ bienal de 68, foram apresentadas ainda peças do mobiliário da Thonet como paradigmas do design moderno mundial (LEON, 2005). A exposição abrangia desenho industrial e comunicação visual, e os seus trabalhos foram expostos utilizando o sistema expositivo desenvolvido pelo IDI - à exceção da exposição da ESDI, elaborada por seus alunos (BERTASO; BRAGA, 2010). ficial da classe média, preconizava-se uma 'democratização' da universidade [...] Painéis, estruturas textos, objetos e projetos expostos, um primoroso trabalho fotográfico desenvolvido pelo novo professor de Fotografia, Roberto Maia, mostraram os resultados de oito anos de trabalho [...]: não ao consumismo como premissa de trabalho; método e racionalidade como meios de desenvolvimento de projeto (SOUZA, 1996, p. 211-213).
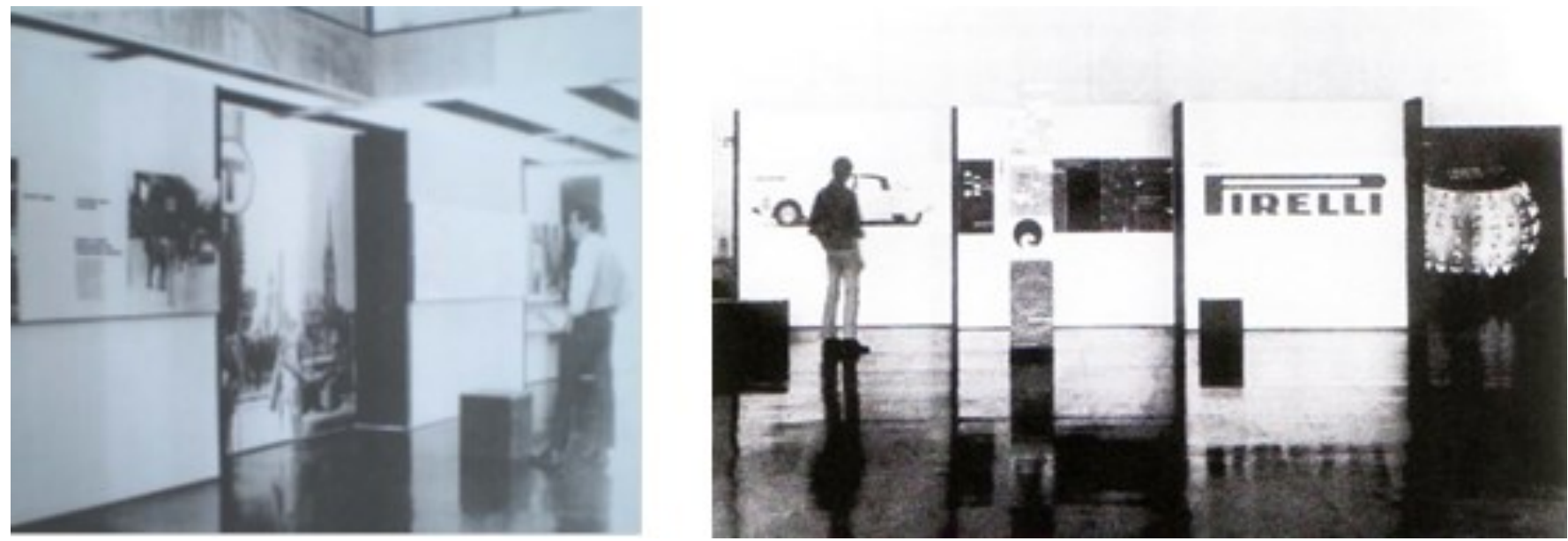

Figura 6-Desenho Industrial 68 Bienal Internacional do Rio de Janeiro, no MAM, na qual se utilizou o primeiro sistema expositivo de Bergmiller. Fonte: Bertaso; Braga (2010); Leon (2005).

Figure 6-Industrial Design 68 International Biennial of Rio de Janeiro, at MAM, in which was used the first exhibition system by Bergmiller. Source: Bertaso; Braga (2010); Leon (2005).

A segunda edição da bienal internacional do Rio de Janeiro teve representação dos países nórdicos Suécia, Dinamarca, Finlândia e Noruega. A exposição, além de objetos domésticos, mostrou ferramentas, máquinas, equipamentos para escolas, hospitais e transportes. A bienal de 1970 apresentou também uma mostra de trabalhos da ESDI e da Faculdade de Arquitetura e Urbanismo da Universidade de São Paulo, FAU-USP, que representavam a metodologia aplicada e os resultados do ensino do design no país (BERTASO; BRAGA, 2010; LEON, 2012; 2005). Sobre a mostra da ESDI na segunda edição da bienal, Souza (1996) pontua:

Tratou-se de uma declaração de fidelidade ao racionalismo, uma forma de preservação doutrinária e, de forma indireta, uma crítica ao ensino superior que se estabelecia então, cada vez mais dirigido à massificação, coerente com a política genericamente irresponsável do milagre econômico. Diante da prosperidade arti-

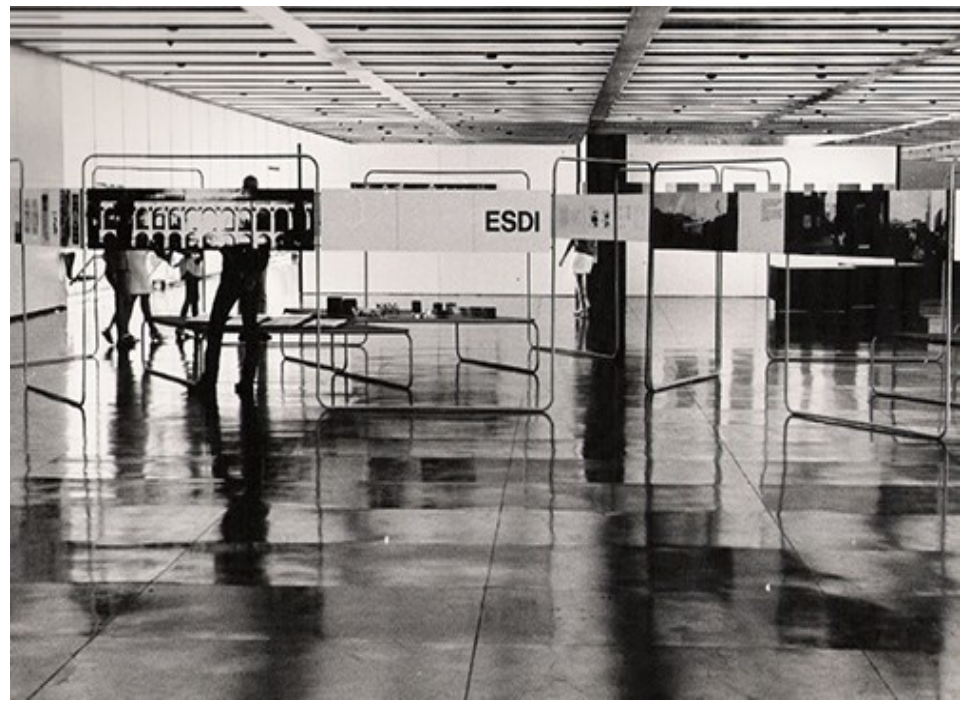

Figura 7-Exposição da ESDI na segunda bienal brasileira de desenho industrial, em 1970. Fonte: Souza (1996).

Figure 7-ESDI exhibition at the second brazilian biennial of industrial design in 1970. Source: Souza (1996).

Já a terceira edição em 1972, Suíça e Alemanha foram os países convidados. Leon (2005) explica que os alemães apresentaram uma seleção de objetos premiados com o selo Gute Form, entre 1969 e 1972. O projeto expositivo da terceira edição da bienal foi desen- 
volvido por Wolfgang Behles e Fritz Keller. Com as exposições internacionais, o IDI contribuiu para a atualização da informação sobre design mundial no Brasil, sendo que a representação nacional atingiu 45 projetos. Novamente, a ESDI participou com dois projetos: $\mathrm{Ho}$ mens Trabalhando e Sinalização Urbana. Estas exposições de discentes incorporam o debate sobre ergonomia em postos de trabalho e, também, o ordenamento urbano, necessário para uma sociedade de massas.

Salienta-se que nessa edição, fica mais evidente certa ruptura com o racionalismo alemão e uma fuga das escolhas construtivistas, especialmente em projetos de comunicação visual (LEON, 2012; 2005). Por seu turno, Souza (1996) informa que o discurso era menos criativo e instigante que nas edições anteriores, e apresentava um realismo crítico com o design alinhado a comissões de estandardização, de exportação, departamentos de aquisições e abastecimento de hospitais e escolas, além de municipalidades responsáveis pelos equipamentos urbanos. Sobreas bienais do Rio de Janeiro, Van Camp e Fontoura (2010) afirmam que

com sua realização contínua e pela sua consistência de concepção e planejamento, além do sucesso de público, demonstraram e provaram, sem nenhuma dúvi$d a$, que mesmo no seu início o design contribuiu de forma definitiva para a construção de uma competência brasileira em áreas técnicas [...]As exposições bienais de design Desenho Industrial 68, Desenho Industrial 70 e Desenho Industrial 72, realizadas no Rio de Janeiro, sem dúvida, cumpriram o papel histórico e pioneiro de difusoras do design como meio de desenvolvimento cultural e industrial do pais (VAN CAMP; FONTOURA, 2010, p. 39).

Além das bienais ${ }^{12}$, outras exposições foram organizadas pelo IDI para a divulgação do design. A exposição Imagem Empresarial, em março de 1970, destacou a identidade visual das companhias aéreas, entre elas, a Lufthansa de autoria de Otl Aicher e também as companhias Varig, SAS, TAP, Panam, Iberia, Braniff, Air France, BUA e Swissair. Em abril do mesmo ano, o Instituto realizou a mostra Talher Contemporâneo, com 60 modelos europeus, que itinerou pelo Brasil, tendo como objetivo mostrar o desenho moderno, despido de adornos, mesmo num objeto tão tradicionalmente ornamentado como o talher (LEON, 2005; SOUZA, 2004).

A partir de 1974, segundo Souza (2004), o IDI passou a dedicar-se a pesquisas aplicadas em design. Uma de suas importantes ações foi destinada ao Ministério da Indústria e do Comércio, que visava tanto à melhoria qualitativa das embalagens para produtos de exportação, como à definição de uma imagem do produto brasileiro no exterior. O resultado daquele trabalho foi o Manual Para Planejamento de Embalagens - edição de recomendações técnicas, funcionais, formais e mercadológicas a serem observadas pela indústria exportadora - além do Curso de Planejamento de Embalagens. Outro apoio didático à iniciativa de implantação do manual foi a exposição Embalagem, Design e Consumo, projetada por Bergmiller em 1976 - sendo que mais tarde, a mostra seguiu por Recife, Salvador, Porto Alegre e São Paulo (LEON, 2005; SOUZA, 2004).

Para Bertaso e Braga (2010), esta foi uma das mostras de maior sucesso do IDI. Além dos suportes e painéis terem sido elaborados em função do caráter itinerante da exposição, a embalagem de transporte foi um item essencial do projeto. Desenvolvidas em função de parâmetros modulares, as caixas de armazenamento e transportes transformavam-se em suportes de comunicação. Este sistema expositivo tinha formas retangula-

\footnotetext{
${ }^{12}$ Após as três primeiras edições, a bienal de desenho industrial seria descontinuada por problemas de custos e prazos, sendo retomada em 1990 e 1992 , em Curitiba (SOUZA, 1996; VAN CAMP; FONTOURA, 2010). A partir de 2006, se consolida a Bienal Brasileira de Design, de caráter itinerante na realização de suas edições.
} 
res e empilháveis, com aplicação de letras brancas (título da exposição) sobre fundo vermelho, que formavam repetições conferindo ritmo e ordenação ao conjunto (figura 8). Após um incêndio no MAM - RJ, em 1978, o IDI teria as suas atividades encerradas.

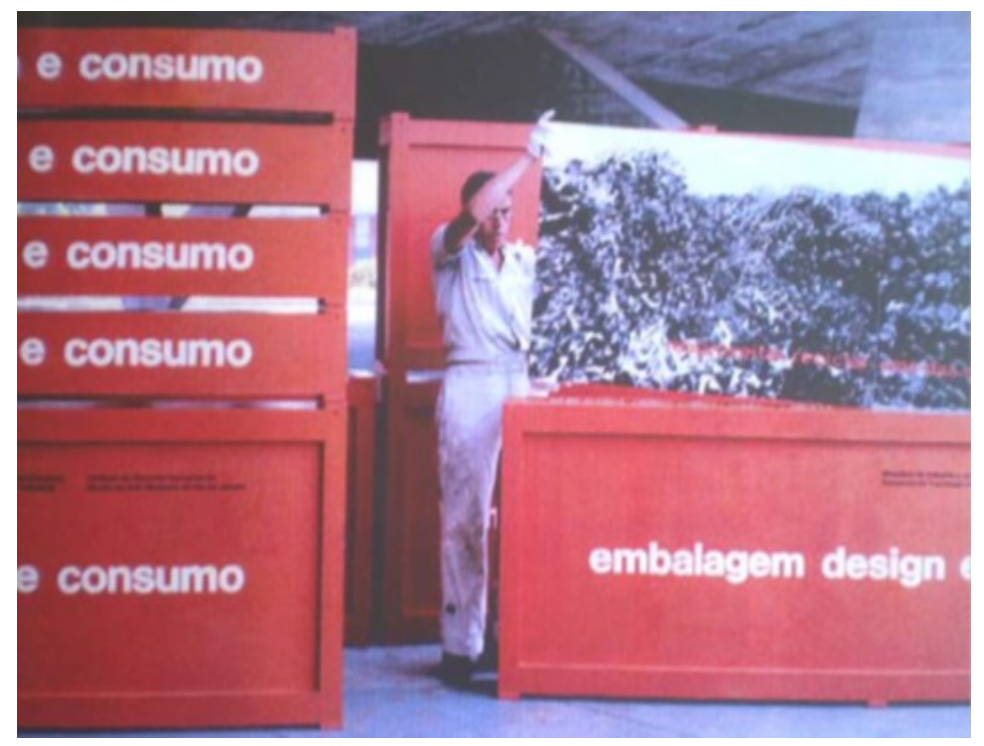

Figura 8-Exposição Embalagem, Design e Consumo. Fonte: Bertaso e Braga (2010).

Figure 8-Packaging, Design and Consumption exhibition. Source: Bertaso and Braga (2010).

Em 1979, Bergmiller projetou o segundo sistema expositivo e supervisionou a sua fabricação. Era apresentado juntamente com um manual que, além das descrições das peças, trazia a metodologia para a correta montagem das exposições. Bertaso e Braga (2010) acrescem que o material era uma aula para a montagem de uma mostra competente:

determina-se ali um modelo de cronograma, o organograma de funções, os técnicos envolvidos, e cada passo necessário à realização dos trabalhos [...] O sistema foi baseado em caracteristicas tidas como essenciais: harmonia formal e estrutural com a obra arquitetônica, versatilidade, facilidade de manutenção, manipulação e montagem, rigidez estrutural, obediência a um conceito sistêmico, utilização de materiais não combustiveis e definição de grandes superficies móveis. Era um sistema modular formado por 12 elementos como painéis, vitrines, suportes e colunas, era composto por peças cujas dimensões obedeciam $30 \mathrm{~cm}$ no sentido horizontal e $25 \mathrm{~cm}$ no sentido vertical. Cada um dos elementos foi projetado em função do tipo de peça a ser exposta (BERTASO; BRAGA, 2010, p. 10-11).

Utilizado pela primeira vez no Salão Nacional de Arte Moderna, o novo sistema expositivo de Bergmiller, assim como o primeiro, teve repercussão e influenciou a expografia contemporânea no Brasil. Formado por paredes auto-portantes, reflete-se em algumas características das montagens atuais: elementos neutros, em material que suporte pintura nas duas faces, além de flexível para diferentes arranjos e obras, conforme figura 9 (BERTASO; BRAGA, 2010).
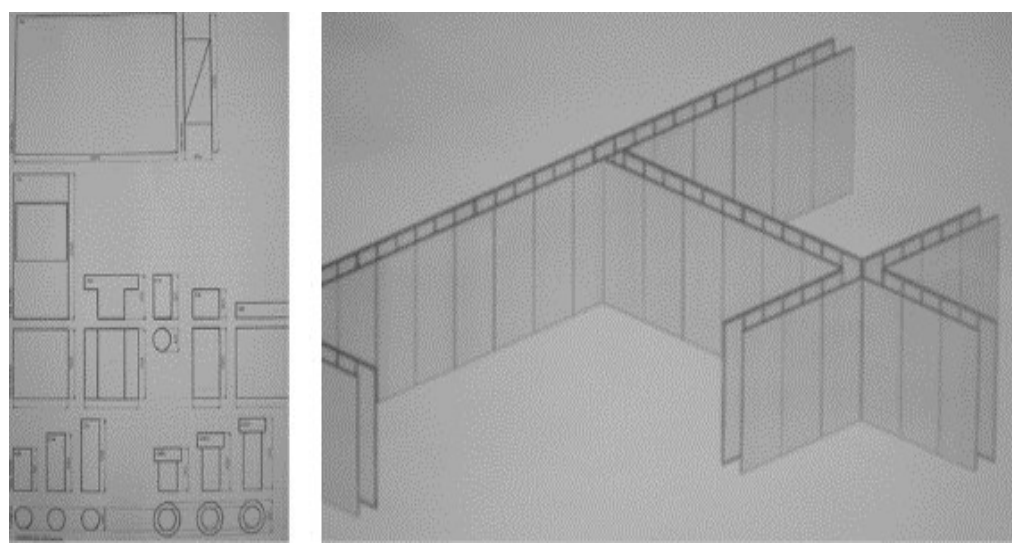

Figura 9-Segundo sistema expositivo de Bergmiller e a organização do espaço. Fonte: Bertaso e Braga (2010).

Figure 9-Second exhibition system by Bergmiller and the organization of space. Source: Bertaso and Braga (2010).

Em conformidade com Souza (2004), a trajetória bem sucedida de Bergmiller foi decorrente de sua autodefinição:

\section{muito mais um designer de ideias e de processos do que um designer de obje- tos. Em relação ao país adotado, é muito clara sua ideia ao afirmar, em 1998, que o 'design em países como o Brasil deve ser prioritariamente orientado para ob- jetivos sociais, que não visam a um lucro imediato. Devem objetivar a racionali- dade do uso e da produção' (SOUZA, 2004, p. 19).}

Apresentando-se como designer de ideias e de processos, Bergmiller demonstra profunda compreensão da realidade brasileira e do estado da arte do design no país. Sua preocupação e sua produção estabelecem fronteiras, ou melhor, balizas que servem de 
referência não somente para aqueles que se dedicam à produção - no caso as indústrias ou empresas que fazem uso do design - mas também orienta o campo profissional evidenciando as urgências do fazer do designer. Ainda dentro da tradição ulminiana de objetividade e racionalidade produtiva, chama a atenção para o papel social do design e do designer em países periféricos. Educar o público consumidor a partir de exposições, apresentar o design e a arte se utilizando dos espaços do museu, talvez se constitua em estratégia mais ampla do que desenvolver projetos de objetos para usos específi$\cos$.

\section{Considerações finais}

Ao concluirmos este breve panorama, importa ressaltar que uma das justificativas para a produção de exposições de design em instituições museológicas, a partir do período moderno, reside no fato de a inserção da atividade emergir em meio ao circuito artístico e cultural do país, à época do desenvolvimentismo. Em grande parte, podemos explicar essa relação pelo perfil das instituições que participaram da implantação do design no Brasil. Assim, a institucionalização do design ocupa um espaço que se não é o mesmo é, ao menos, contíguo. A inserção do design no contexto de industrialização tinha a exposição museológica ora como operação legitimadora, ora como espaço de crítica.

Os museus de arte e as escolas de design dialogaram e urdiram seus destinos em malhas muito próximas. Esta proximidade, que em verdade existe desde os primórdios da profissão, trouxe evidentemente ganhos e perdas. Os ganhos, que são incontáveis, ficam na maior parte das vezes por conta do apoio teórico e metodológico fornecido pela arte e pela arquitetura. Dentre as perdas, talvez a mais evidente seja o fato do design ser associado, em primeira face, à ideia de forma, embora alguns profissionais antecipassem o pensamento sistêmico no ato de projetar, como Bergmiller.
Lina Bo e Pietro M. Bardi, Aloisio Magalhães, Alexandre Wollner, Goebel Weyne e Karl Heinz Bergmiller, dentre outros, estavam muito ligados à cultura brasileira e às artes, em particular. Observamos que boa parte desses nomes revela a presença de imigrantes no cenário artístico cultural brasileiro da época. Assim, é possível compreender que as origens do design de filiação estrangeira, no contexto nacional, refletiram uma visão de mundo e um projeto para modificá-lo - uma relação direta com a educação - por meio do sensível, pela retórica visual daquelas exposições.

No debate sobre aspectos ideológicos que orientaram a inserção do campo no país, Leon (2014), traça um perfil de hibridismo do IAC/MASP no tratamento dos dilemas do design moderno, entre consumo e transformação social, entre identidade nacional e visões importadas, entre tradição artesanal e progresso industrial, entre racionalismo e marketing. Por conseguinte, suas exposições reafirmavam a visão híbrida do diretor Pietro Maria Bardi, como no exemplo da Vitrine das Formas. Já nas exposições do IDI/MAM-RJ, especialmente nas mostras da ESDI nas bienais de desenho industrial, era evidente a crítica ao consumismo e a um pensamento projetual que desconsiderava a posição periférica do país, sendo sintomático o exemplo da mostra $O$ Banquete de Consumo. Desiludida com os rumos tomados pelo design, ainda no início dos anos 1980,Lina Bo Bardi (1994) registrou:

a grande tentativa de fazer do Desenho Industrial a fôrça regeneradora de toda uma sociedade faliu e transformou-se na mais estarrecedora denúncia da perversidade de todo um sistema [...] O esforço contra a hegemonia tecnológica, que sucede no ocidente, e o 'complexo de inferioridade tecnológico' no campo das artes, esbarram na estrutura de um sistema: o problema é fundamentalmente político-econômico. A regeneração através da arte, credo da Bauhaus, revelou-se mera utopia, equívoco cultural ou tranquilizante dos que não precisam [...] Ao suicídio romântico do 'não- 
planejamento', reação ao fracasso tecnocrático, é urgente contrapor a grande tarefa do Planejamento Ambiental, desde o urbanismo e a arquitetura, até o desenho industrial e as outras manifestações culturais. Uma reintegração, uma unificação simplificada dos fatores componentes da cultura (BARDI, 1994, p. 134).

A fala de Lina Bo Bardi, a despeito do tom pessimista, é antecipatória, pois diagnostica uma realidade de inícios do século XXI. O design cada vez mais se distancia de sua vocação como força de transformação social. A formação acadêmica pautada no domínio das técnicas e das tecnologias up to date tem traçado um destino perverso para o designer como um mero replicador de demandas do mercado globalizado.

Assistimos e vivemos uma época repleta de oximoros. Por um lado, o 'complexo de inferioridade tecnológica' percebido pelas artes e apontado por Bardi, encontra eco e reflexo nas sociedades periféricas onde a excelência tecnológica tem se apresentado como um horizonte mais desejado do que alcançado nestas sociedades. Por outro, a desumanização e a impessoalidade promovida pelas tendências homogeneizantes da globalização e da tecnologia, tem levado grupos e indivíduos a reafirmar suas identidades, a reforçar seus laços e investir na diferença se utilizando destas mesmas tecnologias. Com efeito, vale citar a definição recente do ICSID sobre o papel do designer no cenário contemporâneo:

Design é uma atividade criativa cujo propósito é estabelecer as qualidades multifacetadas de objetos, processos, serviços e seus sistemas de ciclos de vida. Assim, design é o fator central da humanização inovadora das tecnologias e o fator crucial das trocas economicas e culturais [...] Design trata de produtos, serviços e sistemas concebidos através de ferramentas, organizações e da lógica introduzidas pela industrialização - não somente quando são produzidos em série (ICSID, 2000).
Portanto, o designer contribui para o bem-estar social ao projetar produtos materiais e imateriais que solucionam problemas humanos. Esta abordagem é compartilhada por designers que colocam ênfase no papel social de sua atuação profissional. Desse modo, Bonsiepe (2011, p. 21) ressalta que humanismo projetual é "o exercício das capacidades projetuais para interpretar as necessidades de grupos sociais e elaborar propostas viáveis, emancipatórias, em forma de artefatos instrumentais e artefatos semióticos”. Isto, na prática, seria focar também nos excluídos, nos discriminados, e voltar-se para a base da pirâmide, que constitui maioria da população, além dos idosos e pessoas com deficiência. Com efeito, deixa-se de empregar o design como ferramenta dominadora para a sustentação do consumismo e sua bagagem obrigatória de degradação ambiental e desigualdade social (BONSIEPE, 2011; MARGOLIN, 2014).

É sob este enfoque humanista que importa a ação interdisciplinar entre design e museologia. A exposição oportuniza um espaço de formação e crítica para a atividade projetual e, em via de mão dupla, ao desvelar a informação manipulada no desenvolvimento de produtos e mensagens visuais, a instituição museológica amplia seus fins educativos e sociais. O design, desde as suas mais remotas origens, sempre esteve ancorado à articulação entre cultura e tecnologia. O próprio espaço do museu, particularmente dos museus históricos, está repleto de objetos, artefatos, utensílios representativos de culturas e identidades diversas. Esta multiplicidade de produtos da cultura material foi projetada e inoculada com significados profundos e complexos e que exigem um grande esforço para serem convocados e, de alguma forma, traduzidos. É aí, nesta tarefa de reapresentação que entra o design de exposição. 
No cenário atual, é possível estabelecer um contraponto otimista à fala de Lina Bo Bardi, com a mostra Bienais de Design: primórdios de uma ideia. Sob a curadoria de Freddy van Camp e Ivens Fontoura, foi uma exposição pertencente à III Bienal Brasileira de Design, em Curitiba, em 2010, que recuperou a história das bienais realizadas em 1968, 1970 e 1972 no Rio de Janeiro, e em 1990 e 1992, em Curitiba. O seu objetivo era "mostrar como já temos uma história significativa de esforços pela difusão da cultura do design em nosso país" (BORGES, 2010, p. 35).Sobre a mostra que retomava as bienais de desenho industrial na III Bienal Brasileira de Design (figura 10), a curadora-geral Adélia Borges (2010) explicita a importância das mostras históricas de design: "a história do design brasileiro só recentemente começou a ser escrita. Se o foco principal de uma Bienal é o presente, ela pode voltar seu olhar para o passado, visando trazer à luz, rememorar e compartilhar legados que nos ajudam a compreender em que ponto estamos e, assim, gestar melhor o futuro" (BORGES, 2010, p. 45).

Em outras palavras, a exposição de design, histórica ou não, possibilita fortalecer a consciência de que já somos detentores de um patamar projetual de excelência. Como alertava Lina Bo Bardi, planejar, projetar e promover encontros mais do que nunca é necessário. De alguma maneira, este tem sido o objetivo deste artigo: ampliar as fronteiras dialógicas entre instituições culturais, design de exposição e a exposição de design,com os exemplos do IAC/MASP e do IDI/MAM-RJ, e sua atuação junto ao ensino e ao setor produtivo. Sabe-se que de algum modo este encontro tem ocorrido, ainda que de modo tímido, e que ele realiza parte do projeto idealizado por aqueles que trabalham com a cultura material, que é o diálogo permanente entre design e indústria. Acredita-se que um dos espaços privilegiados para que este encontro ocorra é o museu.
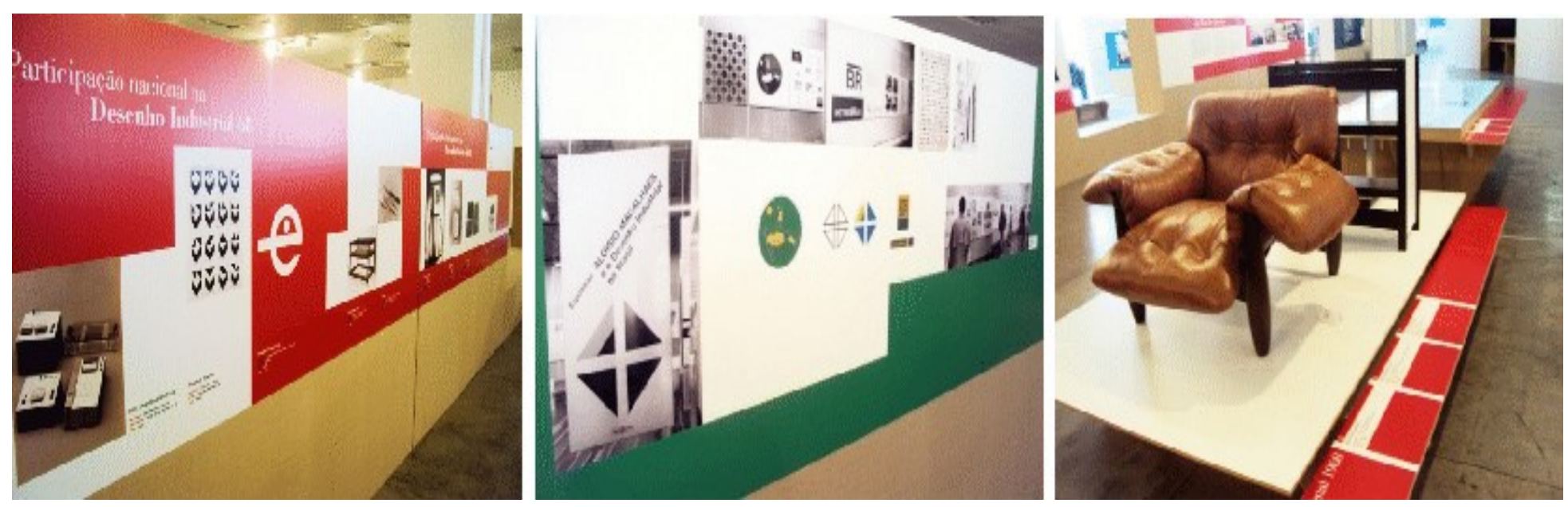

Figura 10-Mostra Bienaisde Design: primórdios de uma ideia, na III Bienal Brasileira de Design, em Curitiba, em 2010. Fonte: banco de imagens dos autores.

Figure 10_Design Biennial: beginnings of an idea exhibition, in the III Brazilian Design Biennial in Curitiba, in 2010. Source: authors' image bank. 


\section{Referências bibliográficas}

ANELLI, Renato Luiz Sobral. Gosto Moderno: o design de exposição e a exposição de design. In: ARQTEXTO, n. 14, UFRGS, 2009.

BARDI, Lina Bo. Museu de Arte de São Paulo: Lina Bo Bardi 1957-1968. São Paulo: Instituto Lina Bo e P. M. Bardi, 1999.

. Tempos de Grossura: o design no impasse. São Paulo: Instituto Lina Bo e P. M. Bardi, 1994.

BARDI, Pietro Maria. História do MASP. São Paulo: Instituto Quadrante, 1993.

BERTASO, Maria Stella Tedesco; BRAGA, Marcos da Costa. Sistemas expositivos projetados por Bergmiller: o caso do MAM-RJ. In: Anais do $9^{\circ}$ Congresso Brasileiro de Pesquisa e Desenvolvimento em Design $-P \& D D e-$ sign. São Paulo: AEND-BR, 2010.

BONSIEPE, Gui. Design, cultura e sociedade. São Paulo: Blucher, 2011.

BORGES, Adélia. A celebração do melhor momento do design brasileiro. In: III Bienal Brasileira de Design.BORGES, A. (Org.) v. 1, 1ª . ed., Curitiba: Centro de Design Paraná, 2010.

BÜRDEK, Bernard E. História, teoria e prática do design de produtos. São Paulo: Blucher, 2010.

CARA, Milena. Do desenho industrial ao design no Brasil: uma bibliografia crítica para a disciplina. São Paulo: Blucher, 2010.

CARDOSO, Rafael. Uma introdução à história do design. São Paulo: Edgard Blücher, 2008.

CURTIS, Maria do Carmo. Funcionalismo: referência histórica para o design social.In: $9^{\circ}$ Congresso Brasileiro de Pesquisa e Desenvolvimento em Design- P\&D Design. Anais...SãoPaulo: UAM, 2010.

DEL PRIORE, Mary; VENÂNCIO, Renato. Uma breve história do Brasil. São Paulo: Ed. Planeta, 2010.

ICSID - International Council of Societies of Industrial Design. Industrial Design. Disponível em: <http:// www.icsid.org/iddefinition.html> Acessado em: 14 out. 2016.

LEON, Ethel. IAC - Primeira Escola de Design do Brasil. São Paulo, Blucher: 2014.

. Design em exposição: o design no Museu de Arte Moderna do Rio de Janeiro (1968-1978), na Federação das Indústrias de São Paulo (1978-1984) e no Museu da Casa Brasileira (1986-2002). Tese de doutorado. Faculdade de Arquitetura e Urbanismo da Universidade de São Paulo - FAUUSP, 2012.

2005 .

Design brasileiro quem fez, quem $f a z=$ Brazilian design who did, who does. Rio de Janeiro: SENAC Rio,

LUPTON, Ellen; MILLER, J. Abbot. $O A B C$ da Bauhaus. São Paulo: Cosac Naify, 2009.

MAGALHÃES, Aloisio. O que o desenho industrial pode fazer pelo país? Por uma nova conceituação e uma ética do desenho industrial no Brasil. Revista Arcos Design. Vol. 1, nº único. Rio de Janeiro: PPDESDI/UERJ, 1998.

MALDONADO, Tomás. Design Industrial. Liboa: Edições 70, 2009.

MARGOLIN, Victor. A Política do Artificial: ensaios e estudos sobre design. Rio de Janeiro, RJ: Civilização Brasileira, 2014.

MELO, Francisco Homem de. O design gráfico brasileiro: anos 60. São Paulo: Cosac Naify, 2008.

NIEMEYER, Lucy. Design no Brasil: origens e instalação. Rio de Janeiro: 2AB, 2007.

SCHINCARIOL, Zuleica. A Seleção do Cartaz para a I Bienal: Diálogos Construtivistas. In: Anais do $5^{\circ}$ Congresso Internacional de Pesquisa em Design - CIPED. Bauru: Unesp, 2009.

SCHWARCZ, Lilia Moritz; STARLING, Heloísa. Brasil: uma biografia. São Paulo: Cia. das Letras, 2015.

SOUZA, Pedro Luiz Pereira de. ESDI: biografia de uma ideia. Rio de Janeiro: EdUERJ, 1996. 

2004. . Homenagem ao designer Karlz Heinz Bergmiller. In: Brasil Faz Design $6^{a}$ Edição. São Paulo: Sebrae, . Notas para uma história do design. Rio de Janeiro: 2AB, 2008.

STOLARSKI, André. Alexandre Wollner e a formação do design moderno no Brasil: depoimentos sobre o design visual brasileiro. São Paulo: Cosac Naify, 2005.

VAN CAMP, Freddy; FONTOURA, Ivens. Bienais de design: primórdios de uma ideia. In: III Bienal Brasileira de Design. BORGES, A. (Org.) v. 2, 1ª . ed., Curitiba: Centro de Design Paraná, 2010.

VERSIANI, Flávio; SUZIGAN, Wilson. O processo brasileiro de industrialização: uma visão geral. Universidade de Brasília: Departamento de Economia, 1990.

WOLLNER, Alexandre. Textos recentes e escritos históricos. São Paulo: Rosari, 2003.

Submissão: 22/05/2016 Aceite: $25 / 10 / 2016$ 